\title{
Scientists pit natural enemies against giant whitefly
}

$\mathrm{T}$ he giant whitefly has made a comfortable life in back yards throughout coastal Southern California and given grief to gardeners who must cope with dying landscape plants and masses of fine, threadlike filaments hanging from leaves. But the insect shouldn't get too comfortable. UC Riverside entomologists are testing two tiny, stingless wasp species against it.

In laboratory tests, the parasitic wasps have shown promise as effective natural enemies of the giant whitefly (Aleurodicus dugesii), which first appeared in San Diego County in October 1992. Each wasp lays a single egg inside a whitefly nymph - an immature insect that clings to the underside of a leaf, feeding until it reaches adulthood. The tiny wasp larva hatches from its egg and spends its 2 -week life feeding on the insides of the whitefly nymph and, in doing so, kills it. A few days later, an adult wasp emerges from the dead whitefly to start the cycle again.

The entomologists recently released the wasps in several locations in San Diego and Orange counties to see if they can survive and reproduce. If the wasps prove effective in the field, they may be a long-term solution to the giant whitefly problem, according to UC Riverside entomologist Tom Bellows.

Biological control programs - which employ natural predator or parasitic insects to suppress populations of insect pests - have become more common as scientists seek to reduce the use of chemical pesticides. Once natural enemies become established, both the pest insects and their enemies coexist below noticeable levels. In 1991 and 1992, UC Riverside scientists stemmed ash whitefly infestations in California and several other states using another species of stingless wasp. Masses of swarming ash whiteflies had forced some urban dwellers to give up backyard barbecues.

Since the giant whitefly was first detected in San Diego County, its population has grown exponentially and spread to infest ornamentals in coastal Southern California as far north as San Luis Obispo.

"I have not seen such a hysterical response from homeowners, retail nurseries and land- scape maintenance personnel (public and private) since the ash whitefly [infestation] severa] years ago," says Orange County farm advisor John Kabashima. "This is definitely a pest which will cause extensive damage and potential and current market-share loss to nursery growers, especially small growers in infested areas."

UC Riverside scientists have found that gian whitefly prefers hibiscus, giant bird-of-paradise, banana, orchid trees and aralia, but it also feeds on bougainvillea, guava, citrus, liquidambar, ornamental plums, acacias, ficus, fruitless mulberry, nasturtium and philodendron, among other landscape plants.

The insects suck sap from the leaves, weakening the plants. Whitefly populations can become extraordinarily high on a single plant, so much so that the waxy substance secreted by the nymphs can form masses of long, threadlike filaments that hang as far as 4 inches from the undersides of leaves. And, the honeydew substance excreted by the adult insects and nymphs promotes growth of a black sooty mold fungus.

Pesticides are largely ineffective, partly because the waxy substance secreted by the nymphs tends to protect them from water-based insecticides.

The two parasitic wasps (Idioporus affinis and Encarsiella noyesi) were found by former UC Riverside postdoctoral scientist David Headrick, while searching for natural enemies of the giant whitefly in Mexico - its presumed native country. The wasps he collected were held in quarantine in Riverside for study and to insure that they themselves would not become pests in the United States. Both species of wasp - unrelated to common stinging wasps - measure about 2 millimeters long.

UC Riverside has been granted release permits by state and federal agencies to test the wasps in the field. Each release site is being monitored weekly to determine if the wasps are

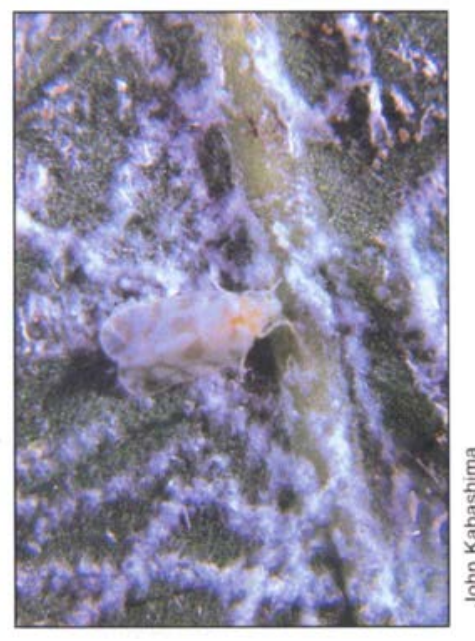

The giant whitefly is so named because it is larger than other whitefly species, about the length of a grain of rice from its head to the tips of its spotted, translucent wings.

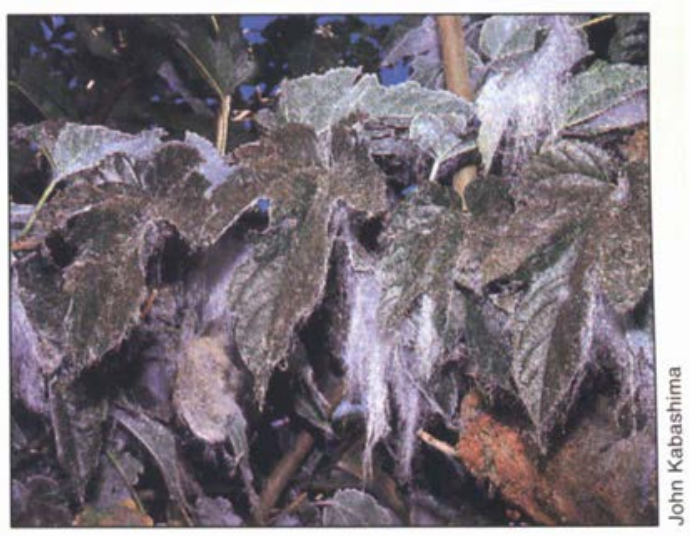

The waxy substance secreted by giant whitefly nymphs can hang as far as 4 inches from the undersides of leaves. 
